\title{
“TRANSLADO TURÍSTICO FUTEBOLÍSTICO": notas sobre a profissionalização no futebol no Amazonas (década de 1960)
}

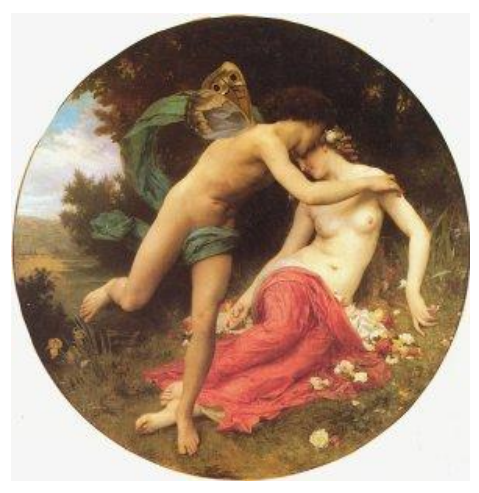

Edson Vitor Lima ${ }^{1}$

Hélio Dantas ${ }^{2}$

\section{Resumo}

O artigo busca realizar uma análise a respeito da profissionalização do futebol amazonense da década de 1960, tendo como fonte de pesquisa a coluna esportiva "Pé na Bola", do Jornal A Crítica no período de 1966-1970. Na primeira parte, será feita uma breve descrição e análise da trajetória das pesquisas sobre futebol no Amazonas. Na segunda parte, a partir da análise da referida coluna jornalística, buscar-se-á compreender as disputas políticas e econômicas nas lideranças de clubes, além do esforço de duas instituições - FAF e ACLEA - de fomentarem uma imagem de "modernização" para o futebol amazonense. A pesquisa analisa como os atletas autóctones foram desvalorizados em decorrência do vertiginoso processo de compra de atletas de outros estados, fomentado tanto pelas lideranças dos clubes quanto pela FAF e ACLEA, gerando consequências negativas para o desenvolvimento pleno do esporte no Estado.

Palavras-chave: Futebol. Amazonas. Profissionalização.

\begin{abstract}
The article seeks to carry out an analysis about the professionalization of the Amazonian football of the 1960s, having as a research source the sport column "Pé na Bola", from the newspaper A Crítica in the period 1966-1970. In the first part, a brief description and analysis of the trajectory of the research on soccer in the Amazon will be made. In the second part, based on the analysis of this journalistic column, we will try to understand the

\footnotetext{
1 Graduado em História - Universidade Nilton Lins. E-mail: edsonbeno@live.com

${ }^{2}$ Mestre em História (PPGH/UFAM). Historiador da Secretaria de Estado da Cultura do Amazonas, Professor do Departamento de História da Universidade Nilton Lins e Pesquisador da Fundação de Amparo à Pesquisa do Estado do Amazonas (FAPEAM). E-mail: lathebiosa@gmail.com
} 
political and economic disputes in club leaderships, as well as the efforts of two institutions - FAF and ACLEA - to foster an image of "modernization" for the amazonan football The research analyzes how the native athletes were devalued as a result of the vertiginous process of buying athletes from other states, fomented by the leaderships of the clubs as well as FAF and ACLEA, generating negative consequences for the full development of the sport in the State.

Keywords: Soccer. Amazonas. Professionalism.

\section{INTRODUÇÃO}

O futebol, conhecido popularmente como a "paixão nacional" do brasileiro, elemento de presença certa nas mídias, ainda é tratado pelo saber acadêmico nacional com alguma reserva. Possivelmente, o título mais antigo nas Ciências Sociais seja o livro de Mário Rodrigues Filho, O negro no futebol brasileiro, publicado pela primeira vez em 1947. Hoje considerado um "clássico" e seguido de várias reedições, o livro é marcado por um enfoque sociológico tributário de Gilberto Freyre, à época, consagrado como um dos mais renomados sociólogos do país.

No que tange à História, pesquisas sobre o tema viriam surgir apenas nos anos 1980. Ainda que pequenos no volume de páginas, os livros História politica do futebol brasileiro, de Joel Rufino dos Santos e O que é futebol?, de José Sebastião Witter, publicados em 1981 e 1990, respectivamente, são textos com forte viés marxista, característica marcante das pesquisas do período.

Ao longo dos anos 1990, outros títulos seriam editados. Vale elencar aqui a Dissertação de Plínio Negreiros, defendida em 1992 na PUC/SP, intitulada Resistência e Rendição: a Gênese do Sport Club Corinthians Paulista e o futebol oficial em São Paulo (1910-1916). Em 1994, Nicolau Sevcenko também publicou importante obra, a saber, Futebol, metrópoles e desatinos; em 1998, Footballmania: uma história social do futebol no Rio de Janeiro (1902-1938) de autoria de Leonardo Affonso de Miranda Pereira pode ser considerado uma grande contribuição. Contudo, somente no final dos anos 
1990 é que a pesquisa histórica voltada especificamente para o futebol iria ganhar contornos institucionais firmes, especificamente, no Laboratório de Estudos do Tempo Presente da Universidade Federal do Rio de Janeiro, de onde nasceria, em 2007, o Laboratório de História do Esporte e do Lazer.

Pelo esforço desses pesquisadores brasileiros, é que atualmente há várias teses, dissertações e artigos, que são fundamentais para a melhor compreensão do esporte e suas respectivas funções na sociedade brasileira.

No âmbito da produção acadêmica local, as pesquisas sobre o futebol amazonense são escassas. $O$ que se tem são trabalhos de memorialistas, como por exemplo, Baú Velho, de Carlos Zamith, publicado em 1999, e Memórias do Esporte no Amazonas e Lembranças do Futebol e do Rádio Amazonense, de Nicolau Libório, publicados em 2009 e 2012, respectivamente.

O único trabalho mais específico é a Dissertação de Mestrado de Tarcísio Serpa Normando, Jogos de bola, projetos de sociedade - por uma história social do futebol na Belle Époque Manauara, defendida em 2003 e não publicada. Neste importante e pioneiro trabalho de pesquisa, o autor analisa como se deu a prática dos mais variados esportes na Manaus do começo do séc. XX. Ele propõe que "a aceitação dos esportes por setores específicos da sociedade foi favorecido pelo desejo de importar uma atmosfera de civilidade e modernização capitalista que marcou a Belle Époque" (NORMANDO, 2003, p. 24). Assim, a ampla recepção da prática desportiva como lazer na belle époque manauara refletia a vontade da elite local ser moderna e civilizada. A fama que tinha a terra amazônica, de um lugar de bárbaros e selvagens, precisava ser suplantada por outras conotações, e as práticas esportivas, principalmente o futebol, iriam se adequar perfeitamente aos interesses elitizados que, "deveria mesclar refinamento social com a preparação e o cuidado com o corpo" (NORMANDO, 2003, p. 36). Essa pesquisa serve, com larga margem, de embasamento para este artigo. 


\section{A prática do futebol no Amazonas}

Em 1906, pode-se datar oficialmente como o primeiro ano em que realmente houve detalhes registrados de partidas de futebol em Manaus. Neste mesmo ano surgia o campo do Parque Amazonense. Segundo Tarcísio Normando (2003, p. 42), "num primeiro momento, procurou-se evitar a entrada de nacionais nas equipes - o Racing Club, por exemplo, gabava-se de ter apenas ingleses em seu elenco". Indiferença essa que não duraria muito. Com vários clubes já praticando com afinco o esporte, é fundada em 1914 a Liga Amazonense de Foot-ball. Em janeiro de 1916 passou a ser denominada de Liga Amazonense de Sports Athléticos LASA, o que durou apenas um ano. Em seguida a Federação Amazonense de Desportos Atléticos - FADA foi fundada em 21 de Novembro de 1917, perdurando até 1966.

\section{Disputas de poder no futebol amazonense da década de 1960}

Os clubes amazonenses que se destacavam na década de 1960 no Amazonas eram: Nacional, Rio Negro, Olímpico Clube, Fast, Sulamérica, Rodoviária, América, São Raimundo e União. Esse clubes, considerados profissionais, disputavam o Campeonato Amazonense, a Copa Norte, o "Nordestão" e a Taça Brasil.

O sucesso dos esportes geralmente está ligado a uma instituição que é encarregada de administrar e sempre gerir os meios para o sucesso do mesmo. As várias transformações e mudanças de nomenclaturas na história da instituição responsável de organizar e administrar o futebol amazonense é um exemplo das mudanças em busca do sucesso ou do desenvolvimento, esperado por aqueles que propõem as mudanças.

No caso do Amazonas, as disputa pelo poder de gerir a prática do futebol no Estado configurou-se com mais força na década de 1960. Neste momento histórico, a assistência do público aos jogos estava em baixa. Os 
torcedores não compareciam aos estádios pela falta de expectativa nos clubes, e porque os mesmos não demonstravam qualquer inovação para uma possível melhoria da qualidade dos jogos, e a instituição responsável (FADA) passava por uma forte crise financeira. Dentro desse contexto, os clubes locais, juntamente com uma instituição, a Associação dos Cronistas e Locutores Esportivos do Amazonas - ACLEA, começaram o processo de desvinculação oficial da FADA, visando fundar uma nova instituição gestora do futebol no Amazonas, que viria ser a Federação Amazonense de Futebol-FAF.

A ACLEA, instituição profissional criada em 1954, detinha uma visão política peculiar, visando a uma profissionalização do futebol amazonense; tal posicionamento era proclamado como "salvador" do futebol local (Jornal A Crítica, 04/03/1966). A ACLEA, a partir de sua fundação, passou a entrar em disputa com a instituição gestora do futebol no Estado, a FADA, pelo controle do futebol no Amazonas. A administração da FADA era tida por seus críticos como "arcaica e medieval", daí as alegações de que o futebol amazonense precisava de uma moderna estrutura para ter visibilidade e qualidade.

A primeira estratégia de ataque foi o uso do silêncio: os meios de comunicação locais se fecharam para o noticiário do futebol regional até segunda ordem da ACLEA. Tal silenciamento perduraria até a criação da FAF. O Jornal A Crítica de 08/10/1966 estampa em sua manchete "C.R.D. devolve futebol ao povo". Fundada a FAF em 26 de setembro de 1966, com um seleto time de homens influentes do meio jornalístico e esportivo assim estava formada sua estrutura:

$\mathrm{Na}$ presidência o jornalista e empresário Flaviano Limongi, na vice o Major Jorge Teixeira, como secretario o Dr. Joaquim Loureiro, tesoureiro o Sr. Norton Pinho, para o conselho técnico foram escolhidos os senhores Luiz Gonzaga de Souza, João Guerra, Sebastião Maia, Raimundo Melo e José Maria Bichara, enquanto o conselho fiscal ficou assim 
constituído: Dr. Fernando Barros, Prof. Alfredo Linhares e Sr. Alfredo Tetenje e outros demais órgãos que estão sendo estudados. (Jornal A Crítica, 29/09/1966).

Os clubes que apoiaram a fundação da FAF foram Rio Negro, Nacional, Fast, Sul América, São Raimundo, Olímpico, União, América, e também as portas estavam abertas para todos os que desejarem tomar parte da nova federação, conforme matéria do Jornal A Crítica de 26/09/1966, intitulada de "Nova Reunião da Federação de futebol Amazonense".

Foi uma batalha árdua, mas por fim o poder da mídia prevaleceu e foi reconhecida oficialmente pela Confederação Brasileira de Desporto - à época presidida por João Havelange - no dia 21 de agosto de 1967. Antes da criação da nova instituição "redentora" do futebol local, o mesmo estava passando por uma crise econômica e administrativa que estava diretamente ligada a FADA, instituição atacada pela mídia diariamente. Ao mesmo tempo em que atacavam, já fomentavam o nome da futura nova administradora do futebol local, criticando a situação dos clubes que estavam, “à beira do abismo, dado o desprestígio do esporte rei na nossa cidade, as fracas arbitragens, os ingressos caros a falta de estádios com capacidade de receber mais e melhor número de torcedores são fatos que entravam seu progresso" (Jornal A Crítica, 30/03/1966).

O grupo midiático, com suas críticas ininterruptas e com seu objetivo de desmoralizar a FADA e, consequentemente, ter o apoio da sociedade amazonense na sua nova empreitada, obteve sucesso. Só que a vitória ainda não era dada como certa, pois a CBD ainda precisava reconhecer e legitimar a nova mentora do futebol amazonense, mas a intensa euforia tomou conta até de alguns deputados na Assembleia Legislativa do Estado, que discursaram e louvaram a nova instituição. E, nas páginas do Jornal A Crítica, aqueles que discursaram em favor da FAF, são vistos pelo jornal como "brilhantes" e "dinâmicos", no caso, José Bernardo Cabral e Renato de Souza Pinto (Jornal A Crítica, 30/09/1966). 
Com a base se solidificando cada vez mais, através da forte ligação entre ACLEA, FAF, clubes e parlamentares, no dia 08 de outubro de 1966 é publicada uma matéria no Jornal A Crítica, intitulada "CRD devolve o futebol ao povo". O Conselho Regional de Desporto a partir de agora validava o alvará provisório de funcionamento da FAF. Na entrevista realizada com Flávio de Souza, ele relata as duas vezes que se encontrou com João Havelange: "fui indicado ao senhor com uma difícil missão, de pedir a desvinculação do futebol amazonense junto a desportista FADA", e acrescenta que "tomou um susto" quando Havelange falou que o presidente da FADA, Laércio Miranda, era seu "compadre". O clima ficou tenso e depois de dois dias se encontraram novamente, só que dessa vez Flavio de Souza estava acompanhado de um advogado enviado diretamente pelo então governador do estado do Amazonas, Arthur Cézar Ferreira Reis, que estava de passagem pelo Rio de Janeiro. Dessa vez logo foi atendido por Havelange, e não esperou às três horas como da primeira vez que estava só.

A partir da legitimação institucional da FAF, a corrida pelo tão prometido progresso no futebol local começava. De início foram postas em ação obras nos dois estádios de Manaus: Colina e Parque Amazonense. Rede elétrica para jogos noturnos, reformas das arquibancadas e gerais, construção de vestiários e também novas exigências rigorosas para os juízes que iriam apitar os jogos da FAF. Desta vez, não há silêncio por parte da mídia, mas uma exposição da atuação. O grupo corporativista sai na frente mostrando para a sociedade a nova maneira de administrar o futebol amazonense. No Jornal A Crítica, autoproclamado "o melhor", eram diárias as matérias enaltecendo a FAF: "Amazonas esportivo aplaude trabalho desenvolvido com êxito pela FAF", "Federação Amazonense de Futebol é sinônimo de trabalho e progresso do nosso esporte", eram alguns dos títulos de matérias veiculadas no jornal. 
Neste processo de luta pela liderança da instituição administradora do futebol baré, ganharia o grupo mais articulado, e a ACLEA era a mais "política", pois sua influência nos estados do Norte era grande, assim como também tinha seus "braços" no Sudeste: o jornalista amazonense Denis de Menezes, que junto à gestora do futebol nacional, CBD, foi de extrema importância para a FAF, pois o mesmo, pela sua influência como radialista e cronista esportivo da cidade do Rio de Janeiro, intervia diretamente pelo grupo junto a essa instituição para a aprovação da nova mentora do futebol local, sendo assim um importante articulador da FAF no Sudeste do país, dando visibilidade para o esporte do Amazonas. O próprio processo de contratação de atletas de fora não teria o êxito que teve, se não fosse Denis de Menezes com seu prestigio de radialista na divulgação e marketing do futebol amazonense no Sudeste.

A instituída FAF, agora mentora por direito do futebol amazonense tem por obrigação de campanha da um novo conceito de administração no futebol do estado:

Daqui por diante as nossas esperanças aumentam e ninguém quer mais um futebol medíocre, desassistido e desamparado. Esse futuro promissor com que sonhamos nos será oferecido pela FAF, ela que veio trazer de volta a alforria do nosso futebol. (Jornal A Crítica, 20/10/1966)

\section{Um novo eldorado do futebol: o Amazonas.}

A partir do momento em que a FAF consegue da um pouco mais de visibilidade ao futebol regional os clubes empolgam-se pela mídia da época, pois a mesma dava ênfase que, os clubes profissionais precisavam urgentemente acompanhar o modernismo que a FAF trouxera para o estado, e assim os clubes começaram a contratar jogadores não mais pela racionalidade que outrora se dava, quando a qualidade do atleta era vista nos jogos e estava em primeiro lugar. Apenas um ano de administração da 
nova mentora do futebol baré, já era possível ver de fato as transformações no âmbito esportivo: jogos à noite, torcidos voltando aos estádios, renda dos clubes aumentando, jogos no meio da semana; foi o "boom" do esporte amazonense em 1967, todos empolgados no ritmo da FAF. No mesmo ano volta para o cenário esportivo amazonense o clube dos "cinco aros", o Olímpico Clube, que para disputar o campeonato precisaria de um elenco forte. Como não tinham base nenhuma, foram os primeiros a importar mais de cinco jogadores de uma só vez.

O problema para os atletas regionais começava em 1967, quando o time do Olímpico, contando com apenas três jogadores autóctones: “o goleiro Procópio, Russo e Sales, e o resto do time Sidney, Xerem, Jarbas, Cascadura, Gilberto e Iralto eram cariocas, enquanto Faustino e Santiago foram importados do Pará" (LIBORIO 2009, p. 20). Era dado início ao desprestígio do atleta regional em vista ao importado. Com a experiência bem sucedida do Olímpico, na sequência todos os outros clubes iriam aderir a contratações em massa de importados, com consequências negativas sem tamanho para o desenvolvimento do esporte local.

No final da década de 60 ocorreu um fluxo muito grande de jogadores de outros estados para o Amazonas. O papel da mídia primeiramente foi divulgar a modernidade, dizendo que os clubes precisavam contratar atletas, investir e mudar a concepção de amador para o profissional. Os dirigentes então não pararam mais de importar, pois a tendência do momento era a valorização da qualidade dos jogadores do Sudeste frente ao regional. As muitas contratações que estavam ocorrendo e gerando um alto índice de jogadores de fora em Manaus começava a despertar as criticas de torcedores e daquela que no inicio apoiou a FAF - a mídia. Os jornais nessa época possuíam grande influência principalmente no meio esportivo. Suas crônicas fomentavam a discussão sobre futebol, sendo agressivas ou modestas dependendo de que lado o "criticado" estaria. 
Nas contratações de jogadores de outros estados, os primeiros a jogar pelos clubes amazonenses, foram os atletas do: Pará, Rondônia, Roraima, Acre, e Amapá. No início o interesse pelos jogadores se dava a partir do momento em que os clubes desses estados vinham jogar em Manaus; a partir daí as propostas eram feitas aos jogadores. Essas primeiras contratações ainda não prejudicavam diretamente os atletas locais, que vinham ganhando espaço nos clubes.

A visibilidade de Manaus como novo polo futebolístico "desejado e cobiçado" deu-se a partir das idas dos treinadores de férias em outros estados, como no caso do Olímpico Clube em 1969, cujo treinador Sebastião Sena, que estava em férias no estado do Pará e o goleiro Dari, no Rio de Janeiro, ambos com abertas intenções de acertar a contratação de sete jogadores, (Coluna Pé na Bola, Jornal A Crítica, (03/01/1969). Nota-se que no time do Olímpico neste momento eram dois os responsáveis pelas contratações. Os outros clubes amazonenses também tinham os seus articuladores nas transações, como o cronista esportivo amazonense Denis Menezes, que trabalhava na Rádio O Globo do Rio de Janeiro e tinha ligação direta com a ACLEA e a FAF.

"O senhor Denis Menezes é o grande divulgador do futebol amazonense no sul do país, transmitidas nas emissoras de maior gabarito, impressas em revistas e transmitidas em comentários elogiosos, este é o trabalho do radialista Denis Menezes, além da presença dos melhores juízes e das maiores equipes, Vasco Flamengo, Santos, Cruzeiro, Fluminense" fala do senhor Flaviano Limongi. Jornal A Crítica, 05/08/1969)

Denis Menezes foi o grande articulador no sentido de dar visibilidade ao Amazonas no âmbito esportivo, e também indicava juízes e clubes famosos para o estado. Por essas e outras "benfeitorias" para o futebol amazonense, Flaviano Limongi homenageou o seu confrade com a "criação da taça Denis de Menezes, o 
campeão da taça seria o clube profissional que se sagrasse bicampeão amazonense ou conquistasse três títulos esparsamente" (Jornal A Crítica, 05/08/1969).

Além dos profissionais dos clubes e da mídia encarregados na contratação direta ou indireta de jogadores de fora, até mesmo o presidente da FAF apoiava as importações:

O presidente Flaviano Limongi não esconde a satisfação e o entusiasmo diante das contratações feitas e as outras em desmanche. E diz o presidente: "tenho a impressão que essa Taça Amazonas e o campeonato de 69 vão esquentar. Todos os clubes estão se dinamizando, contratando técnicos e jogadores e eu prevejo um sucesso sem precendentes em rendas e em bons espetáculos". (Coluna Pé na Bola, Jornal A Crítica, 15/01/1969).

O futebol amazonense teria tido de fato um progresso em quantidade de jogadores, não em qualidade; os muitos que aqui chegavam não eram tão profissionais como se pensava, e a coluna esportiva no início das contratações dava crédito à importação, depois quando os clubes estavam abarrotados de jogadores importados, a crônica via-se no papel de criticar os mesmos que outrora eram elogiados, e no caso dos jogadores regionais, só eram lembrados que "existiam" nessas horas de criticas como vemos a seguir:

Há quem afirme que o Rio Negro completará dezessete jogadores vindos de fora. E isto nos parece demais, teria havido planificação? - dezessete não será número demasiado, inclusive prejudicial ao elemento local inteiramente marginalizado? (Coluna Com o pé na bola, Jornal A Crítica, 08/02/1969).

O jogador regional só era lembrado na mídia depois da inflação de jogadores no estado, e quando a qualidade das importações contratadas não satisfazia a mídia, então entrava em cena a crônica esportiva comentando as mazelas e as falhas nas administrações dos clubes: 
Nuvens pesadas estão caindo sobre o futebol amazonense. Ainda ninguém se apercebeu do fato mais que existe, existem os clubes por não se planificarem, por não se organizarem por não medirem e compararem receitas com despesas breve estarão na insolvência e tudo terminará. (Coluna Com o pé na bola, Jornal A Crítica, 14/02/1969)

A ambiguidade da crônica esportiva é vista em vários momentos dessa coluna. Temos o exemplo do Rio Negro Clube, quando o colunista escreve que:

O seu departamento de futebol iniciou exatamente por onde todos deveriam começar, contratou um técnico de comprovada eficiência um gerente da equipe - este foi o sábio e acertado passo - depois então o próprio técnico apontou e trouxe os jogadores. É esse o roteiro, tem que ser esse o trabalho agora as coisas vão mudar. (Coluna Com o pé na bola, Jornal A Crítica, 22/01/1969)

O problema é esse, não é só do Rio Negro, é de todos os grupos profissionais que não organizaram seus departamentos de futebol em bases racionais e, sobretudo empresarias. Gasta-se dinheiro às pampas com contratações mal feitas, precisa-se de um ponta de lança, mas contrata-se dois zagueiros, dispensa-se profissionais bonzinhos, gente de casa que custavam duzentos contos por mês, e contratam outros bonzinhos lá fora por trezentos e quatrocentos contos. (Com o pé na bola, Jornal A Crítica, 25/03/1969)

É a partir dessas contradições que se deve entender as relações que se dão nesse meio esportivo amazônico. Existe uma relação de poder entre as três instituições ligadas do futebol: Jornal A Crítica, FAF e Clubes, no qual o desejado progresso seria o alvo. A palavra "progresso", aliás, era certa nas páginas dos detentores da comunicação. Os clubes amazonenses não tinham estrutura para aderirem na perda de capital com as contratações dos jogadores de fora como fizeram no 
"boom" que começou em 67. Mas a reboque do que estava acontecendo e pressionados pelo fator "ter que contratar", precisavam mostrar que também estavam se modernizando, confirmando a orientação do momento: tanto o Jornal A Crítica quanto a FAF, as duas instituições sempre foram as articuladoras do futebol amazonense; a FAF com seu poder instituído de criar e legislar sobre os campeonatos e torneios no Amazonas e o Jornal com seu "dever" de fomentar ao público os acontecimentos do esporte, fossem verdadeiros ou não, o importante era ter matéria escrita nas paginas do jornal.

O poder da mídia em relatar que o futebol amazonense estava em crescente ascensão dava privilégios gigantescos para a FAF frente a outras instituições ligadas ao futebol brasileiro, vemos os comentários nas páginas do jornal A Crítica no momento da passagem do presidente da FAF pelo Rio de Janeiro:

Flavio nas suas andanças pelo Rio fez mais sucesso e mais publicidade do Amazonas que todos os embaixadores que lá tivemos e temos. É só o poder do futebol aliado ao indiscutível trabalho de Limongi que lá como aqui tem amigos, e consequentemente os meios de divulgação necessários e imprescindíveis ao êxito. (Jornal A Crítica, 10/04/1969)

Neste momento o Jornal estava declarando que a Amazônia estava sendo mais reconhecida no Brasil pelo seu futebol, do que as outras áreas de interesse econômico e social, e também observamos o homem político que era Flaviano Limongi nas suas articulações com amigos e mídia que seriam imprescindíveis aos seus êxitos.

Propagava-se um futebol amazonense desenvolvido, à altura de outros polos futebolísticos. Contudo, a realidade do futebol amazonense era outra. Poucos eram os clubes que tinham campos de qualidade para treinamento, e os que não tinham viviam a mendigar campos para treinar, e eram os que mais importavam jogadores: Rio Negro, Olímpico e Fast: "não adianta elenco caríssimo sem campo para treinar", alfinetava a Coluna Pé 
na Bola de 12 de agosto de 1969. Os estádios que existiam, Colina e Parque Amazonense ainda não tinham estrutura de qualidade: os campos não tinham marcações adequadas, faltavam banheiros, segurança, acesso para a torcida etc.

O grupo responsável pela crônica esportiva "Com o pé na bola" por vezes mantinham a lei do silêncio e não comentavam nada, outras vezes só falavam do chamado progresso que o futebol estava passando e pela qualidade na administração de Flaviano Limongi, e também comentavam das boas contratações dos importados, e raramente mostravam a verdadeira face do esporte baré: o "caos" e a "falência".

O trecho abaixo parece ser uma exceção a essa regra:

A bancarrota está à vista, o eldorado do futebol é Manaus, clubes presos a contratações idiotas com os técnicos, elencos estúpidos de sucata importada, gastando fortunas com elencos medíocres, jogadores, alguns rebotalhos que aqui chegam e são logo contratados a peso de ouro, assinam e passam a ficar de molho. Inventam contusões, dor de barriga, nó na tripa e o diabo e a gente vai suportando tudo. Em meio a toda essa bagunça com tanta gente ruim ninguém pode formar um conjunto ou uma equipe séria e respeitável. A deficiência do nosso futebol e sua consequente queda nos gráficos técnicos reside nessas licenciosidades administrativas. Nosso futebol é o tipo do sujeito liso que levanta empréstimos no agiota julgando-se rico quando na verdade é um teso e toca a jogar dinheiro fora queimando pianas de dez milongas nos charutos da inconsequência. (Coluna Pé na Bola, Jornal A Crítica, 13/08/1969).

Esse era o verdadeiro progresso do futebol amazonense, realidade que não era divulgada na fala do senhor Flaviano Limongi: Manaus estava se tornando um depósito de jogadores de outros estados, principalmente do Sudeste, que chegavam aos montes; os clubes consequentemente se endividando e indo no caminho da falência, enquanto os jogadores autóctones ficavam esquecidos à própria sorte. $\mathrm{Na}$ mesma página, um 
comentário sobre os atletas juvenis, descritos como "craques autênticos" que "perdem-se no esquecimento mofados e olvidados", também é sintomático dessa realidade.

\section{Considerações Finais}

De acordo com a análise aqui realizada, podemos fazer algumas considerações interpretativas.

Todo o processo de profissionalização do futebol amazonense na década de 1960 e o ritmo ávido de contratação de mão de obra de fora geraram, inevitavelmente, o "abandono criminoso do elemento local", (Jornal A Crítica, 03/01/1970). Um grande número de jogadores barés estavam agora impossibilitados de se desenvolverem no esporte da sua região, pois o excesso de jogadores que aqui aportavam fazendo uma espécie de "translado turístico futebolístico", fez com que os poucos progressos galgados pelos jogadores locais não se efetivasse de maneira mais sólida.

Semelhantemente, o alto valor econômico com que os de fora eram contratados, fazia com que atletas autóctones fossem submetidos a salários muito inferiores em relação aos que aqui chegavam. Por essa opção dos clubes amazonenses, em dar preferência aos de fora, ocorreu uma grande desistência daqueles que vinham subindo de categoria e se profissionalizando. Assim, o fortalecimento, investimento e preparação em gerações de atletas amazonenses para atuar nos clubes, infelizmente, nunca foi uma prática levada a efeito pelas lideranças, tanto da FAF quanto dos clubes.

A vinda maciça de jogadores para o polo amazonense de futebol afetou diretamente a relação de identidade cultural e social com o povo local. Olhando para a história do futebol no Amazonas, houve uma época em que os estádios amazonenses eram motivos de intensa agitação, torcedores com suas bandeiras tremulantes ao vento tinham total 
identificação com os clubes e os jogadores, justamente por conhecer a maioria deles. Segundo o técnico Flávio de Souza, existia nessa época o chamado "esquenta sol", que era o jogo dos juvenis antes dos clubes profissionais, um celeiro de atletas que atraía o interesse das multidões.

A partir da criação da FAF, coube a essa instituição a responsabilidade de administrar e dar uma nova imagem de "modernidade" para o futebol regional. Foi possível perceber essa orientação nos inúmeros relatos expostos nesta pesquisa. Uma fala do próprio presidente da Federação nas entrevistas para os jornais da época é salutar: "é um estímulo para os clubes profissionais que lutam com imensas dificuldades para manter plantéis caros e proporcionar bons espetáculos ao público, razão de existir da Federação Amazonense de Futebol", (Jornal A Crítica, "F.A.F FAZ HOMENAGEM COM TAÇA PARA CLUBES” 05/08/69). A fala do presidente da Federação, Flaviano Limongi, quando se refere a "plantéis caros", é bem típica do momento que passava o futebol regional naquela época, onde os clubes amazonenses estavam dando ênfase na contratação de jogadores de outros estados gerando um gasto de capital muito elevado para as suas realidades.

Fica muito óbvia a falta de interação da sociedade amazonense com os clubes locais, pela perda da referência com os jogadores regionais. No estado do Amazonas não há no atual momento em que este artigo está sendo escrito nenhum jogador tido como "craque da casa", que possa convencer e atrair a sociedade para prestigiá-lo nos jogos, e a porcentagem de torcedores que atualmente vai aos jogos acompanhar e torcer pelos tradicionais clubes do Amazonas é muito inferior em relação aos outros polos futebolísticos do Brasil: a média de público nos campeonatos estaduais está assim classificada: "Pernambuco (9.134), Goiás (6.220) e São Paulo (6.122) são os Estados com maior média de público; por outro lado, Maranhão (825), Piauí (843) e Espírito Santo (895). são os campeonatos com menor média de público". 
Talvez, uma das diferenças desses outros polos de futebol possa ser a valorização, investimento e o reconhecimento de jogadores regionais desde a categoria de base até chegar ao profissional.

A se crer na lógica salvacionista e deslumbrada da FAF e dos clubes na década de 1960, seria "natural" que hoje um esporte como o futebol estivesse plenamente desenvolvido. Contudo, esse desenvolvimento ainda não chegou. De fato, o que se pode constatar é que, tanto FAF quanto ACLEA hoje são instituições desprestigiadas e os clubes estão em situação de calamidade.

\section{Referências}

Coluna esportiva Pé na Bola do Jornal A Crítica, de 1966-70.

NORMANDO, Tarcísio Serpa. Jogos de bola, projetos de sociedade: por uma bistória social do futebol na Belle Époque Manauara. Manaus: Dissertação (Mestrado) - ICHL/UFAM, 2003. 